\title{
Tribute to Professor Hartmut Derendorf-1953 to 2020: The gentle giant of quantitative clinical pharmacology
}

\author{
Stephan Schmidt ${ }^{1}$
}

Published online: 2 March 2021

(C) The Author(s), under exclusive licence to Springer Science+Business Media, LLC part of Springer Nature 2021

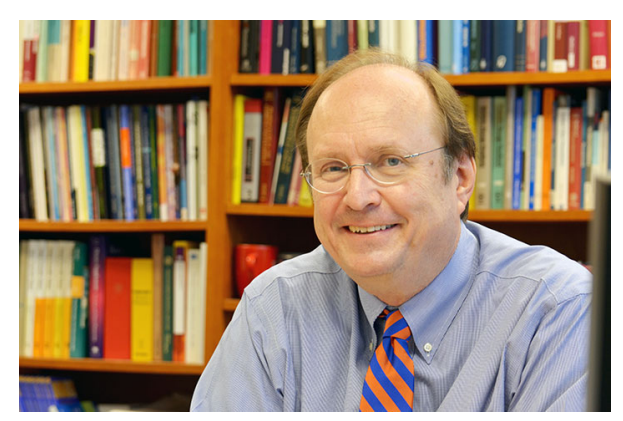

On Monday, November 23, 2020 Prof. Hartmut Derendorf passed away unexpectedly at the age of 67 in Gainesville, Florida. Hartmut was born on August 6, 1953, in Dortmund, Germany. He earned his B.S. in pharmacy (1976) and his $\mathrm{PhD}$ (1979, summa cum laude) from the University of Münster, Germany before joining the University of Florida (UF) as a post-doctoral fellow under the supervision of Prof. Ed Garrett. He was scheduled to return to Germany as faculty but he met his future wife, Kerry Estes, who was a Ph.D. student at UF at the time. Hartmut joined the Department of Pharmaceutics at UF as faculty in 1983, where he rose quickly through the ranks. He retired as a Distinguished Professor in 2018 after nearly 30 years of service as Department Chair. Only 1 year later, Hartmut returned to the College part-time to spearhead the establishment of an online pharmacometrics program.

Prof. Derendorf served as president of the American College of Clinical Pharmacology (ACCP, 2006-2008) and the International Society of Anti-Infective Pharmacology (ISAP, 2004-2006). He received the Nathaniel T. Kwit Memorial Distinguished Service Award of ACCP, the Research Achievement Award in Clinical Science of the

Stephan Schmidt

sschmidt@cop.ufl.edu

1 Department of Pharmaceutics Lake Nona (Orlando), Center for Pharmacometrics \& Systems Pharmacology, University of Florida, 6550 Sanger Road, Office 464, Orlando, FL 32827, USA
American Association of Pharmaceutical Sciences (AAPS), the Volwiler Award of the American Association of Colleges of Pharmacy (AACP), the ACCP Distinguished Investigator Award, the First Leadership Award of the International Society of Pharmacometrics (ISoP), the Merit Medal of the Westphalian Chamber of Pharmacy, the University of Utrecht Faculty Award, the Gerhard Levy Distinguished Lectureship from the University of Buffalo, the Barre Prize from the University of Montreal, multiple UF Research Foundation Professorship Awards, and two different UF endowed professorships. In addition, he received numerous teaching awards, including the ACCP Mentorship Award, the American Society for Clinical Pharmacology and Therapeutics (ASCPT) Mentor Award, and the Doctoral Advisor/Mentoring Award (2009 and 2018), the Teaching Improvement Award, the Howard Hughes Medical Institute Distinguished Mentorship Award, and the International Educator of the Year Award at UF. He also served as the 18th University of Florida Distinguished Alumni Professor.

Much has been said and written about Hartmut's accomplishment and merits since his unexpected and premature passing. While he was undoubtedly one of the giants in the quantitative clinical pharmacology arena with over 500 manuscripts, 23 textbooks, and nearly 1000 scientific presentations at national and international conferences, his true strength resided at the interpersonal level, as a mentor, as a colleague, as a friend. Prof. Derendorf was the primary mentor of more than $70 \mathrm{PhD}$ students and 40 post-doctoral fellows as well as hundreds of international exchange students and visiting scientists. Among his trainees, you will find the current list of who is who in clinical pharmacology in industry, academia, and regulatory agencies around the world. "Once a Gator, always a Gator" was not only a phrase that Hartmut liked to use but it also represents his attitude of continued mentorship and guidance, far beyond the time when the "official mentoring" was over. 
You never saw him upset or say a bad word about anyone. Instead he would listen, have a light-hearted story, and provide advice with the big picture in mind. Hartmut was friendly to everyone and treated them with respect. He gave everyone a chance, no matter who they were or where they came from. He stayed humble and true to himself despite his many accomplishments. When I first contacted Hartmut as an outgoing pharmacy student in Germany about a 6-month internship at the University of Florida, he simply said: "I will be giving a talk in Garmisch-Partenkirchen next week, so why don't you come by so that we can chat over a cup of coffee?". This seemed unusual to me at the time that a world-renown expert and keynote speaker of the conference would make time for a scientific nobody to talk about an internship, but, that was Hartmut. It also marked the beginning of a life-long friendship. His scientific ingenuity, mentorship, teaching style, and counsel, shaped me and many others to who we are today.

Hartmut was passionate about teaching and research but he always put the practical application front and center. He encouraged others, including his students and trainees, to think outside the box and critically evaluate existing paradigms. He did not do so by force but by working with others presenting his point of view in a gentle and unassuming manner, leaving room for debate and occasional disagreement. Hartmut was also a tireless advocate for advancing pharmacy training in Germany by re-adjusting its focus to the patient. He outlined the need for a curriculum change in countless presentations, discussion, and articles, where he invited all stakeholders to the table to seek solution that ensure that the profession stays fit for the future.

Outside of work, Hartmut was enthusiastic about his favorite soccer (Borussia Dortmund) and college football (Florida Gators) teams and sought every opportunity to follow their games on TV or, better yet, in person. He also loved attending performances at the Gainesville orchestra with Kerry. Over the years, the two of them welcomed countless musicians, scholars, scientists, and students into their home, providing an opportunity for people from all parts of the world to meet, share traditions, and celebrate their differences. Hartmut's and Kerry's hospitality during these events was always unparalleled and earned them many friends and admirers around the globe. These events were also an embodiment of who Hartmut was, a gentle and kind human being.

Hartmut's premature passing certainly leaves a big hole in the lives of many people but his legacy lives on in the many people that he touched and the spirit that he installed in all of us. For that we are eternally grateful! May he rest in peace.

Funding Not applicable.

\section{Compliance with ethical standards}

Conflict of interest The author declares no conflict of interest relative to this article.

Publisher's Note Springer Nature remains neutral with regard to jurisdictional claims in published maps and institutional affiliations. 